\title{
Induction of heme oxygenase- I by cobalt protoporphyrin enhances the antitumour effect of bortezomib in adult T-cell leukaemia cells
}

\author{
RS Hamamura', JH Ohyashiki*, ${ }^{*, 2}$ R Kurashina',3, C Kobayashi', Y Zhang', T Takaku' and K Ohyashiki' \\ 'Department of Internal Medicine, Tokyo Medical University, Tokyo, Japan; ${ }^{2}$ Intractable Immune System Disease Research Center, Tokyo Medical \\ University, Tokyo, Japan; ${ }^{3}$ Department of Clinical Pharmacology, Tokyo University of Pharmacy and Life Sciences, Tokyo, Japan
}

Adult T-cell leukaemia (ATL) is a lethal neoplasia derived from HTLV-I-infected T lymphocytes frequently exhibiting nuclear factor$\kappa \mathrm{B}(\mathrm{NF}-\kappa \mathrm{B})$ activation. Despite the use of various treatment regimens, the prognosis of ATL is poor, and new treatment strategies are urgently needed. We therefore explored the effect and the molecular mechanism of a proteasome inhibitor, bortezomib, in ATL cells. We found bortezomib-induced cell death, and bortezomib suppressed constitutive NF- $\kappa$ B activation via $I-\kappa \mathrm{B}$ stabilisation in three ATL cell lines (TaY, MT-2 and MT-4). An oligonucleotide DNA microarray analysis of TaY cells revealed upregulation of genes encoding heat shock proteins (HSPA IA, STIPI, HSPA IB, and HSPCA), genes related to protein folding (CDC37 and ANAPC5), Fasassociated factor I (FAFI) and an oxidative stress-related gene, heme oxygenase- I (HMOX-I), known to be a target gene of hypoxiainducible gene-I alpha (HIF-I alpha). Cobalt protoporphyrin induced HMOX-I, instead of HIF-I alpha expression and increased bortezomib-induced apoptosis in the presence of pharmacologically effective doses of bortezomib. In contrast, zinc protoporphyrin downregulated HMOX-I expression, thereby partially inhibiting bortezomib-induced cell death. This indicates that HMOX-I may modulate anticancer effects of bortezomib in ATL cells, and could be a molecular target in treating ATL patients.

British Journal of Cancer (2007) 97, 1099- I 105. doi: I0.1038/sj.bjc.6604003 www.bjcancer.com

Published online 25 September 2007

(C) 2007 Cancer Research UK

Keywords: adult T-cell leukaemia; proteasome inhibitor; bortezomib; heme oxygenase- I

Adult T-cell leukaemia/lymphoma (ATL), an aggressive malignancy of CD4 + lymphocytes, is caused by the retrovirus HTLV-1 (Matsuoka and Jeang, 2005). Adult T-cell leukaemia/lymphoma is resistant to chemotherapy and has a very poor prognosis, which underlines the need for new therapeutic approaches. Leukaemia is preceded by oligoclonal expansion of HTLV-1-infected activated T cells, as a result of the viral transactivator protein Tax expression, which activated various cellular genes including CREB/ATF, AP1, and NF- $\kappa$ B (Sun and Yamaoka, 2005).

Activated nuclear factor-kappa B (NF- $\kappa$ B) was reported in HTLV-1-associated cells, and has been implicated in resistance to anticancer agents and apoptosis. In resting lymphocytes, NF- $\kappa \mathrm{B}$ is sequestrated in cytoplasm, where it is inactivated by association with inhibitory I- $\kappa$ B subunit (Pierce et al, 1997). Upon stimulation, $\mathrm{I}-\kappa \mathrm{B} \alpha$ protein is phosphorylated, and subsequently degraded by the proteasome, resulting in the release of an active NF- $\kappa \mathrm{B}$ that translocates into the nucleus and subsequently activates the transcription of the target genes (Karin and Ben-Neriah, 2000). Tax can activate the NF- $\kappa \mathrm{B}$ pathways through direct interaction

\footnotetext{
* Correspondence: Dr JH Ohyashiki, Intractable Immune System Disease Research Center, Tokyo Medical University, 6-7-I, Nishi-shinjuku, Shinjuku-ku, Tokyo 160-0023, Japan; E-mail: junko@hh.iij4u.or.jp Revised 16 August 2007; accepted 21 August 2007; published online 25 September 2007
}

with the IKK complex, which causes I- $\kappa \mathrm{B} \alpha$ to be phosphorylated, ubiquitylated, and subsequently degraded by proteasomes; however, de novo ATL cells frequently lose Tax expression, thereby escaping from cytotoxic T lymphocytes (Furukawa et al, 2006).

The proteasome inhibitor, bortezomib (also known as VELCADE or PS-341), represents a new class of anticancer drugs which has been shown to inhibit the growth and/or progression of human cancers, including multiple myeloma (Mitsiades et al, 2002; Rajkumar et al, 2005; Cavo, 2006; Fisher et al, 2006). Although it has been theoretically hypothesised that bortezomib abrogates the degradation of $\mathrm{I}-\kappa \mathrm{B}$, which blocks the transcriptional activity of $\mathrm{NF}-\kappa \mathrm{B}$, recent studies demonstrated that bortezomib elicits activation of multiple pathways in cancer cells, such as endoplasmic reticulum (ER) stress and reactive oxygen species (ROS) pathways (Fribley et al, 2004; Nawrocki et al, 2005; Obeng et al, 2006; Pérez-Galán et al, 2006; Yang et al, 2006). More recently, HIF-1 alpha has been shown to determines the sensitivity of endothelial cells to the proteosome inhibitor bortezomib (Veschini et al, 2007).

Despite the fact that bortezomib affects several pathways critical for the survival of HTLV-1-positive and -negative malignant T cells (Satou et al, 2004; Nasr et al, 2005), the underlying mechanism by which bortezomib inhibits ATL cell growth has not been fully elucidated. We therefore attempted to clarify the molecular pathway which might be involved in bortezomib-induced cell death. 


\section{MATERIALS AND METHODS}

\section{Reagents and cell cultures}

Bortezomib was kindly provided by Millennium Pharmaceuticals Inc. (Cambridge, MA, USA). In all experiments, an IL-2-dependent ATL cell line, TaY, which has been established and well characterised in our laboratory (Zhou et al, 1998; Ojima et al, 2005; Takaku et al, 2005), was used in this study. Early passages of TaY cells were retrieved and grown in RPMI 1640 with $10 \%$ FBS and $20 \mathrm{U} \mathrm{ml}^{-1}$ of IL-2 (Roche Diagnostics, Mannheim, Germany). Two IL-2-independent ATL cell lines (MT-2 and MT-4) (Miyoshi et al, 1982), and an HTLV-1-negative T-cell line (Jurkat) (Gillis and Watson, 1980) were also used in a part of our study. After obtaining written informed consent, peripheral blood mononuclear cells (PBMCs) were isolated from two patients with ATL by FicollHypaque. Cobalt protoporphyrin (CoPP) was purchased from Frontier Scientific (Logan, UT, USA). Zinc protoporphyrin (ZnPP) was purchased from Alexis Biochemicals (San Diego, CA, USA).

\section{Cell viability and apoptosis assay}

The inhibitory effect of bortezomib on cell growth was assessed by a cell counting kit (Wako Chemicals, Tokyo, Japan). Briefly, the cells $\left(5000 \mathrm{well}^{-1}\right)$ were incubated in triplicate in a 96 -well plate in the presence or absence of indicated test samples at a final volume of $0.1 \mathrm{ml}$ for $24 \mathrm{~h}$ at $37^{\circ} \mathrm{C}$. Thereafter, $0.01 \mathrm{ml}$ of tetrazolium salt, WST-1 was added to each well. After 2 -h incubation at $37^{\circ} \mathrm{C}$, the optical density (OD) at $450 \mathrm{~nm}$ was measured using a 96-well multiscanner autoreader with the extraction buffer used as a blank. Cell viability was expressed as a percentage (OD of the experiment sample/OD of the control $\times 100)$. For detection of apoptosis, the Annexin V-binding capacities of the treated cells were examined by the Annexin V-biotin apoptosis detection kit (Calbiochem, La Jolla, CA, USA) using an Agilent 2100 Bioanalyzer (Agilent, Wilmington, DE, USA), according to the supplier's instructions.

\section{Evaluation of NF- $\kappa$ B activity}

The DNA-binding activity of NF- $\kappa \mathrm{B}$ was quantified by enzymelinked immunosorbent assay (ELISA) using Trans-AM NF- $\kappa \mathrm{B}$ p65 Transcription factor assay kit (Active Motif North America, Carlsbad, CA, USA).

\section{Western blotting}

Cells were washed twice in phosphate-buffered saline (PBS) and cell pellets were lysed in electrophoresis buffer and boiled for $10 \mathrm{~min}$. The equivalent of $30 \mu \mathrm{g}$ protein was loaded onto each lane of a $10 \%$ tris-glycine gel. The separated protein was blotted onto a filter. After blockage of nonspecific binding sites with BlockAce (Dainippon-Sumitomo Pharma, Osaka, Japan), the filter was incubated with antibodies for $60 \mathrm{~min}$ at room temperature; anti$\mathrm{I} \kappa \mathrm{B}$ (Abcam Plc, Cambridge, UK), anti-HMOX-1 (Stressgen Bioreagents, Ann Arbor, MI, USA), anti-HIF (Novus Biologicals, Inc., Littleton, CO, USA) and anti-GAPDH (Abcam Plc). After washing, the blots were incubated for $60 \mathrm{~min}$ with horseradish peroxidase (HRP)-linked anti-mouse IgG (Amersham Biosciences, Buckinghamshire, UK). Signals were visualised using an ECL western blotting detection reagents and analysis system (Amersham Biosciences).

\section{RNA isolation and labelling}

TaY cells were treated with $0.5-100 \mathrm{~nm}$ of bortezomib for $24 \mathrm{~h}$. After treatment, cells were harvested, and total RNA was extracted using an RNeasy Mini Kit (Qiagen, Germantown, MD, USA). The amount of RNA was measured by NanoDrop (NanoDrop Technologies, Wilmington, DE, USA), then the quality of extracted
RNA was checked using a 2100 Bioanalyzer (Agilent Technologies, Wilmington, DE, USA). A Label Star array kit (Qiagen) was used for cDNA labelling according to the supplier's instructions as reported previously (Zhang et al, 2006).

\section{Oliginucleotide DNA microarray}

We designed a pathway-focused low-density oligonucleotide microarray (Novusgene Inc., Tokyo, Japan) which contains 667 selected genes related to cell growth, cell cycle, apoptosis, transcription, DNA repair and cell stress responses (GPL 3837). For dual-colour analysis, cDNA obtained from untreated TaY cells was labelled with $\mathrm{Cy} 3$ as a reference, and cDNA obtained from the bortezomib-treated cells was labelled with Cy5. Hybridisation was carried out automatically using GeneTAC Hybstation (Genomic Solutions, Ann Arbor, MI, USA), as reported previously (Takaku et al, 2005).

\section{Data analysis and statistic validation}

The hybridisation signals were scanned by GenePix 4000B (Axon Instruments, Union City, CA, USA). For statistical analysis of gene expression, we utilised a GeneSifter ${ }^{\circledR}$ (VizXLabs, Seattle, WA, USA). Analysis of variance (ANOVA) and Student's $t$-test were done using GeneSifter ${ }^{\circledR}$. $P$-values of less than 0.05 were considered to indicate a statistically significant difference and the BenjaminiHochberg algorithm was used for estimation of false discovery rates (Zhang et al, 2006).

\section{Real-time reverse transcriptase-PCR (RT - PCR)}

To confirm the microarray results, we performed RT - PCR by ABI Prism 7700 Sequence Detection System (Applied Biosystems, Foster City, CA, USA) as reported elsewhere (Ohyashiki et al, 2005). We utilised Taqman gene expression assays (Applied Biosystems), and the amount of gene expression in each sample was evaluated as a percent with respect to the standard curve generated from a serial dilution of quantitative PCR human reference total RNA (Stratagene, La Jolla, CA, USA). The obtained data from GAPDH were used to standardise the sample variation in the amount of input cDNA.

\section{RESULTS}

\section{Bortezomib-induced cell death in ATL cell lines}

We first examined the effect of bortezomib on ATL cell lines, TaY, MT-2, MT-4 and a HTLV-1-negative T-cell line, Jurkat, in vitro by a cell-counting assay. The median inhibitory concentration $\left(\mathrm{IC}_{50}\right)$ of bortezomib for TaY was $5 \mathrm{nM}$, that for MT-2 was $4.5 \mathrm{nM}$, that for MT-4 was $10 \mathrm{nM}$ and that for Jurkat was $30 \mathrm{~nm}$, respectively (Figure 1A). The expression level of Tax was not affected by bortezomib-treated ATL cells (data not shown). To study whether or not the cell death induced by bortezomib was apoptosis, we analysed the bortezomib-induced cell death by annexin V staining. Cells were treated for $24 \mathrm{~h}$ with different concentrations of bortezomib, then stained with annexin V-Cy5. The results showed apoptosis in a dose-dependent manner, indicating that bortezomib induced apoptosis of ATL cell lines (Figure 1B); cell death was also confirmed by morphology (Supplementary file).

\section{Bortezomib suppresses constitutive NF- $\kappa$ B activation via $\mathrm{I}-\boldsymbol{\kappa} \mathrm{B}$ stabilisation in ATL cell lines}

We then investigated the DNA binding of NF- $\kappa \mathrm{B}$ by an ELISA assay. Cells were treated with bortezomib for different periods of time. We found the DNA-binding capacity of NF- $\kappa$ B decreased in a time-dependent manner, indicating an inhibitory effect of $5 \mathrm{~nm}$ of 
bortezomib on NF- $\kappa \mathrm{B}$ activation in TaY cells (Figure $2 \mathrm{~A}$ ). The decreased activity of NF- $\kappa$ B was also evident in MT-2 and MT-4 after $3 \mathrm{~h}$ exposure to bortezomib; DNA-binding activity of NF- $\kappa \mathrm{B}$
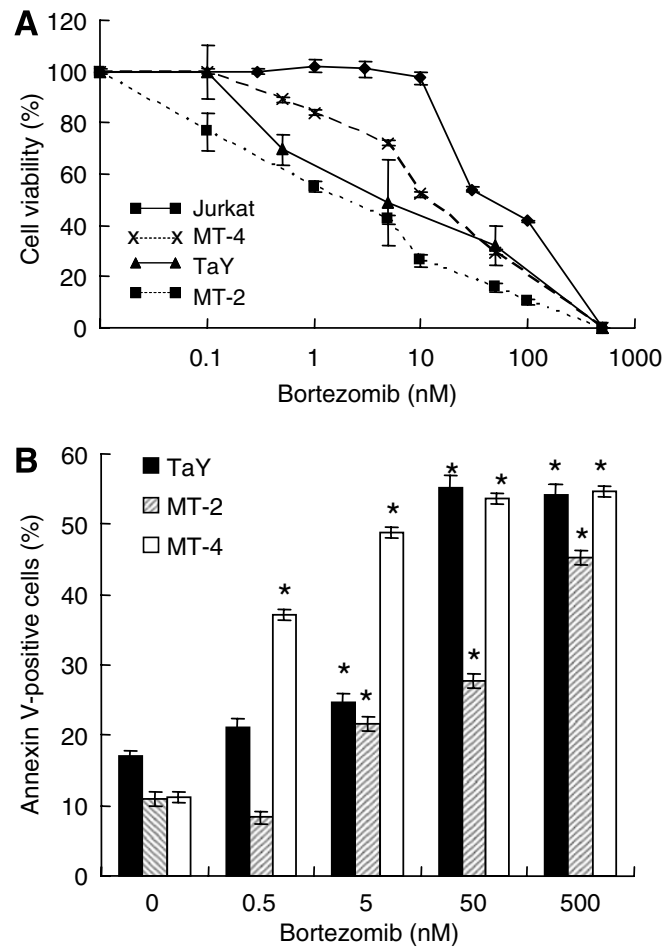

Figure I (A) Cytotoxity of bortezomib on TaY, MT-2, MT-4 and Jurkat. Cells were cultured in the presence or absence of increasing doses of bortezomib $(I-500 \mathrm{nM})$. The percentage of viability is plotted with respect to untreated cells. The results are shown as means ( \pm s.d.) percentage of viability from triplicate cultures with repeated experiments. (B) Bortezomib induced apoptosis in ATL cell lines (TaY, MT-2 and MT-4). Cells were cultured in the presence of bortezomib for $24 \mathrm{~h}$. Cell death was analysed by an annexin $\mathrm{V}$-biotin apoptosis detection kit. Apoptosis is expressed as a percent of Annexin $\vee$-positive cells in bortezomib-treated cells.
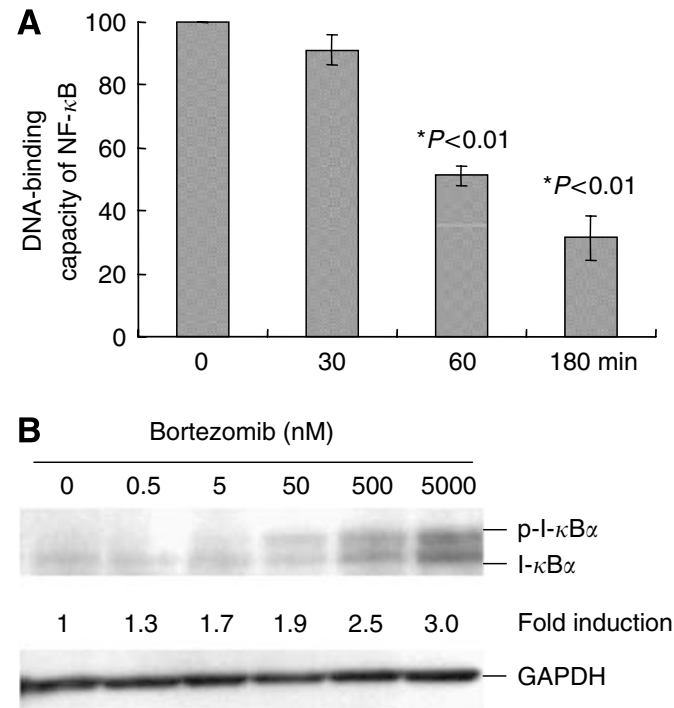

Figure 2 (A) DNA-binding capacity of NF- $\kappa$ B in TaY cells. TaY cells were cultured in the presence of bortezomib for the indicated periods $(0-180 \mathrm{~min})$, harvested and subjected to EMSA. (B) Expression of $\mathrm{I}_{-} \mathrm{B} \mathrm{B} \alpha$ in TaY cells. Whole cell extracts ( $30 \mu \mathrm{g} / \mathrm{lane}$ ) of TaY cells are immunoblotted with specific antibodies against $\mathrm{I}-\kappa \mathrm{B} \alpha$ and GAPDH. Accumulation of $\mathrm{I}-\kappa \mathrm{B} \alpha$ and phosphorylated $\mathrm{I}-\kappa \mathrm{B} \alpha$ were observed in a dose-dependent manner. after bortezomib treatment was $26.8 \%$ in MT-2 and $17.0 \%$ in MT-4 cells, respectively, compared to those in untreated cells. In order to clarify the inhibitory effect of bortezomib on the NF- $\kappa \mathrm{B} / \mathrm{I}-\kappa \mathrm{B}$ cascade, we analysed the protein level of I- $\kappa \mathrm{B} \alpha$ in TaY cells after $24 \mathrm{~h}$ treatment with bortezomib. Consistent with the decreased DNA-binding activity of NF- $\kappa \mathrm{B}$, bortezomib induced the accumulation of I- $\kappa \mathrm{B} \alpha$ in TaY cells (Figure 2B). Accumulation of I- $\kappa \mathrm{B} \alpha$ was also confirmed in MT-2 and MT-4.

\section{Gene expression profile of bortezomib-treated TaY cells}

To further understand how bortezomib induced apoptosis in ATL cells, we used TaY cells treated with bortezomib or vehicle control

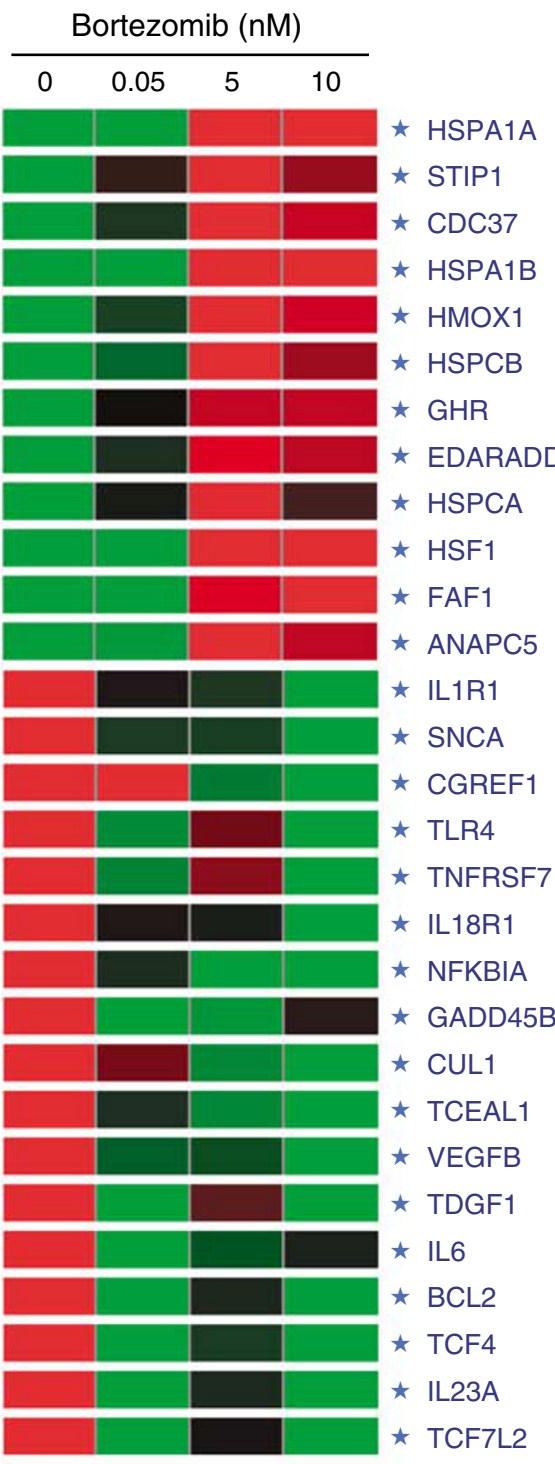

Legend:

$-2$

0

2

$\star: P<0.05$

Figure 3 The molecular signature of bortezomib-treated TaY cells. ANOVA analysis was performed by GeneSifter ${ }^{\mathbb{R}}$ using microarray analysis data deposited in GEO (GSE5794). Genes whose expression levels are greater (red) or lower (green) in bortezomib-treated TaY cells compared to those in untreated cells were navigated by GeneSifter ${ }^{\mathbb{R}}$. They are also listed in Table I. 
for short time periods, and microarray analysis was performed using in-house prepared oligonucleotide DNA microarrays (NCBI Gene expression omnibus, GSE5794, unreleased). Differential expression was analysed using a GeneSifter ${ }^{\circledR}$ (Figure 3). Upregulated or downregulated genes in bortezomib-treated TaY cells (expression level in the sample was four-fold greater or lower than in untreated TaY cells) are summarised in Table 1. In TaY cells, bortezomib induced upregulation of genes encoding heat shock proteins (HSPA1A, STIP1, HSPA1B and HSPCA), genes related to protein folding (CDC37 and ANAPC5) and Fas-associated factor (FAF1) known as an apoptosis facilitator. Upregulation of HMOX-1, which is known to be a target gene of hypoxia-inducible gene-1 alpha (HIF-1 alpha), was notable in bortezomib-treated TaY cells. The results obtained from microarray data were consistent with those analysed by real-time RT-PCR and the induction of HMOX-1 after treatment with pharmacological concentrations of bortezomib was more than 100-fold compared to untreated cells (Figure 4C). Downregulation of vascular endothelial growth factor (VEGF) beta, IL6 and BCL2 were also evident, as previously identified in human multiple myeloma cells following bortezomib-induced apoptosis. Downregulation of a subset of cytokines and cytokine receptors (i.e. IL1R1, IL18R1, IL23A) was also noted.

\section{Induction of HMOX-1 by CoPP enhances the antitumour effect of bortezomib in ATL cells}

Based on the results obtained from the differential expression pattern, we in particular focused our study on a gene closely related to oxygen stress, i.e., HMOX-1. To determine the possible role of HMOX-1 in bortezomib-induced apoptosis in TaY cells, we examined the change of apoptotic effect by adding the HMOX-1 inducer, CoPP, or the HMOX-1 inhibitor, ZnPP. Although CoPP and $\mathrm{ZnPP}$ did not affect the cell growth of TaY cells in the absence of bortezomib (data not shown), we found that CoPP significantly enhanced the cytotoxity and bortezomib-induced apoptosis in $\mathrm{TaY}$ cells (Figure 4A and B). In contrast, ZnPP partially inhibited bortezomib-induced cell death in TaY cells with pharmacologically effective dose of bortezomib (Figure 4A and B). Real-time RTPCR and western blot analysis revealed that CoPP significantly enhanced HMOX-1 in TaY cells (Figure 4C and D). To determine whether HMOX-1 induced the antiproliferative activity of bortezomib via HIF-1 alpha or not, we performed real-time RT-PCR; however, upregulation of HIF-1 alpha was not evident (Figure 4E left). Western blot analysis also revealed that HIF-1 alpha was not significantly elevated after treatment of bortezomib in TaY cells (Figure 4E right). This indicates that upregulation of HMOX-1 rather than HIF-1 alpha affects the antitumour effect of bortezomib.

To ascertain whether involvement of HMOX-1 in bortezomibinduced cell death is not restricted in TaY cells, we analysed the effect of CoPP in MT-2 and MT-4. Upregulation of HMOX-1 by CoPP enhanced sensitivity to bortezomib in MT-2 and MT-4, indicating that this phenomenon is consistent with the results obtained from TaY cells (Figure 5A).

\section{Gene expression levels of HMOX-1 in bortezomib-treated ATL patient' sample}

To validate whether genes extracted in the current study indeed reflect molecular pathways in bortezomib-treated ATL cells, we analysed the gene expression levels of HMOX-1 in bortezomib-

Table I Identification of genes affected by bortezomib treatment

\begin{tabular}{|c|c|c|c|}
\hline Gene accession \# & Gene name & & $P$-value (ANOVA) \\
\hline (a) Upregulated genes & ose expression & el was greater than four-fold compared to those in untreated cells & \\
\hline NM_005345 & HSPAIA & Heat shock $70 \mathrm{kDa}$ protein IA & 0.000012 \\
\hline NM_006819 & STIPI & Stress-induced-phosphoprotein I (Hsp70/Hsp90-organizing protein) & 0.000037 \\
\hline NM_007065 & CDC37 & CDC37 cell division cycle 37 homologue & 0.000036 \\
\hline NM_005346 & HSPAIB & Heat shock $70 \mathrm{kDa}$ protein IB & 0.000001 \\
\hline NM_002133 & HMOXI & Heme oxygenase (decycling) | & 0.015313 \\
\hline NM_007355 & HSPCB & Heat shock protein 90 kDa alpha (cytosolic), class B member I (HSP90ABI) & 0.000033 \\
\hline NM_000163 & GHR & Growth hormone receptor & 0.001547 \\
\hline NM_080738 & EDARADD & EDAR-associated death domain & 0.000078 \\
\hline NM_005348 & HSPCA & Heat shock protein $90 \mathrm{kDa}$ alpha (cytosolic), class A member I (HSP90AA I), transcript variant 2 & 0.00178 \\
\hline NM_005526 & HSFI & Heat shock transcription factor I & 0.006578 \\
\hline NM_00705। & FAFI & Fas (TNFRSF6)-associated factor $\mid$ & 0.006247 \\
\hline NM_016237 & ANAPC5 & Anaphase-promoting complex subunit 5 & 0.011988 \\
\hline (b) Downregulated ger & whose expressic & level was lower than four-fold compared to those in untreated cells & \\
\hline NM_000877 & $|L| R \mid$ & Interleukin I receptor, type I & 0.012833 \\
\hline NM_000345 & SNCA & Synuclein, alpha & 0.000001 \\
\hline NM_006569 & CGREFI & Cell growth regulator with EF-hand domain I & 0.004154 \\
\hline NM_I38556 & TLR4 & Toll-like receptor 4 & 0.000122 \\
\hline NM_001242 & TNFRSF7 & Tumour necrosis factor receptor superfamily, member 7 & 0.000002 \\
\hline NM_003855 & $|\mathrm{L}| 8 \mathrm{R} \mid$ & Interleukin 18 receptor | & 0.007924 \\
\hline NM_020529 & NFKBIA & Nuclear factor of kappa light polypeptide gene enhancer in B-cells inhibitor, alpha & 0.000013 \\
\hline NM_015675 & GADD45B & Growth arrest and DNA-damage-inducible, beta & 0.000001 \\
\hline NM_003592 & CULI & Cullin I & 0.008025 \\
\hline NM_004780 & TCEAL I & Transcription elongation factor A (SII)-like I & 0.000001 \\
\hline NM_003377 & VEGFB & Vascular endothelial growth factor B & 0.000002 \\
\hline NM_003212 & TDGFI & Teratocarcinoma-derived growth factor I & 0.000759 \\
\hline NM_000600 & IL6 & Interleukin 6 & 0.01754 \\
\hline NM_000633 & $\mathrm{BCL} 2$ & B-cell CLL/lymphoma 2 (BCL2) & 0.000054 \\
\hline NM_003199 & TCF4 & Transcription factor 4 & 0.000052 \\
\hline NM_016584 & IL23A & Interleukin 23, alpha subunit p/9 & 0.000001 \\
\hline NM_030756 & TCF7L2 & Transcription factor 7-like 2 & 0.000006 \\
\hline
\end{tabular}

List of genes in Table I correspond to the heat map shown in Figure 3. Gene accession number, full name of each gene and statistical significance are shown above. 

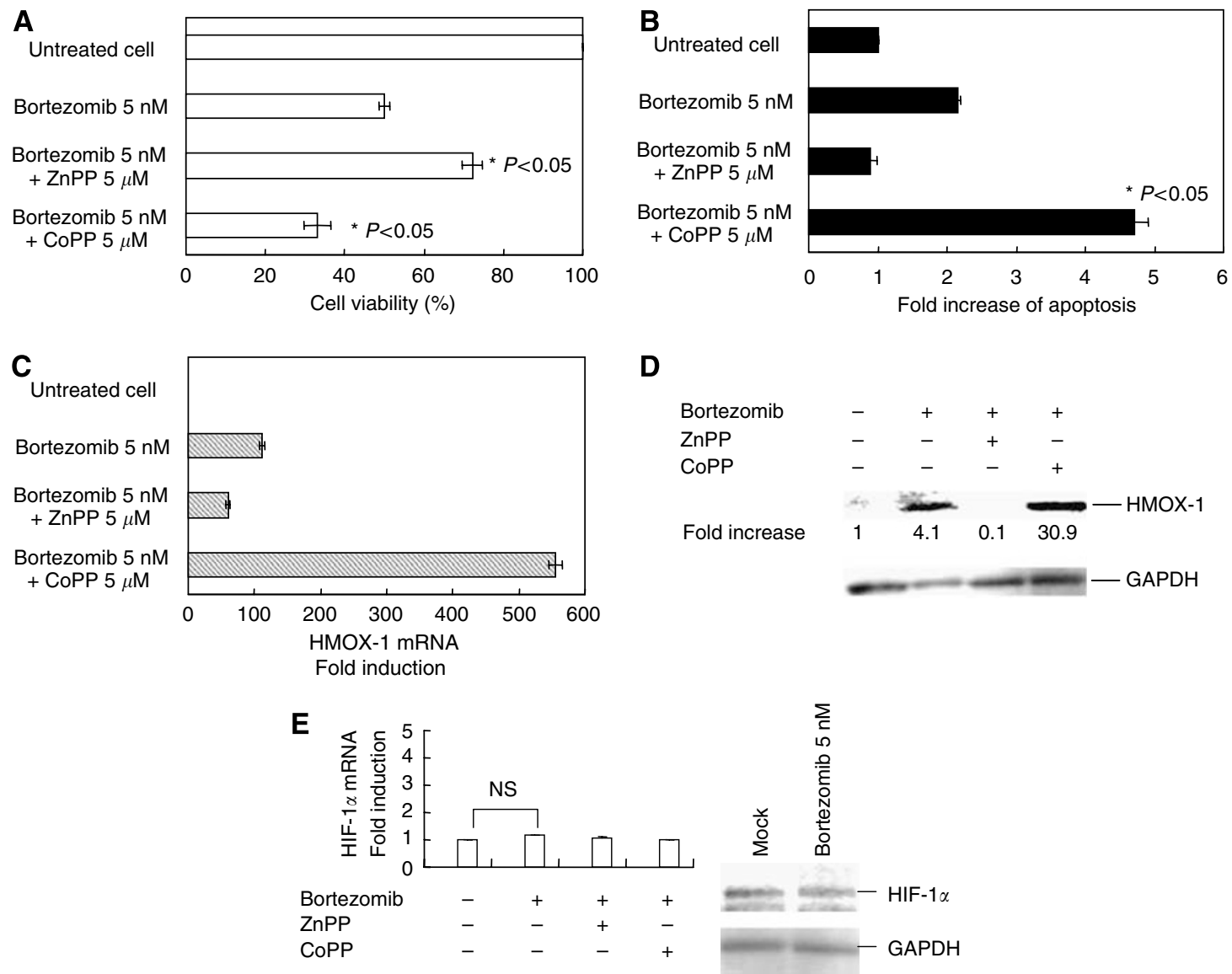

Figure 4 Effect of CoPP and ZnPP in bortezomib-induced cell death. TaY cells were cultured with CoPP or ZnPP in the presence of bortezomib. (A) The percentage of cell viability was plotted with respect to untreated cells. (B) Apoptosis was expressed as fold increases of annexin $V$-positive cells in bortezomib-treated cells compared to those in untreated cells. (C) Fold induction (or reduction) of HMOX gene expression measured by real-time RT-PCR. (D) Western blotting of HMOX-I and GAPDH. Fold increases were expressed as a signal of HMOX-I/GAPDH in the specimen with respect to those in untreated cells. (E) HIF-I alpha expression in bortezomib-treated TaY cells (real-time RT-PCR, left; western blotting, right)

treated TaY cells and ATL cells obtained from two patients. The HMOX-1 expression level was remarkably elevated in bortezomibtreated fresh ATL cells as well as an ATL cell line (TaY). This indicates that the molecular pathway involving HMOX-1 may play an important role in de novo ATL cells treated with bortezomib (Figure 5B).

\section{DISCUSSION}

In this study, we demonstrated that the mechanism of the antitumour effect of bortezomib on ATL cells involves oxygendependent gene regulation in addition to the $\mathrm{I}-\kappa \mathrm{B} \alpha / \mathrm{NF}-\kappa \mathrm{B}$ pathway. Based on the results obtained from gene expression profiling, we in particular focused on HMOX-1, as representative of oxygen-dependent gene regulation in bortezomib-induced apoptosis. We found that bortezomib induced HMOX-1 expression at the transcriptional level as well as at the protein level. HMOX-1, an inducible enzyme that catalyses oxidative degradation of heme to form biliverdin, carbon monoxide and free iron has recently been implicated in the regulation of angiogenesis via VEGF activity (Morse and Choi, 2005). Evidence suggests that expression of HMOX-1 is induced in response to ROS (Morse and Choi, 2005). Bortezomib was reported to induce ROS generation in various cancer cells such as non-small-cell lung cancer, leukaemia cells, and head and neck squamous cell carcinoma. ROS was therefore implicated as the primary cause for bortezomib-induced apoptosis of those cells (Ling et al, 2003; Fribley et al, 2004; Yu et al, 2004; Landowski et al, 2005). Recent reports have demonstrated that $\mathrm{NF}-\kappa \mathrm{B}$ indirectly inhibits ROS generation (Sakon et al, 2003; Kamata et al, 2005); however, the intracellular ROS balance may be regulated by multiple pathways, therefore, it is still uncertain whether ROS generation is due to NF- $\kappa \mathrm{B} / \mathrm{I}-\kappa \mathrm{B}$ inhibition cascade in bortezomib-treated cancer cells.

Oxygen regulation is a complex process that has special relevance in the progression of cancer. Cells subjected to hypoxia (reduced ability of oxygen) undergo transcriptional changes that promote increased anaerobic metabolism, angiogenesis and other adaptive responses (Semenza, 2003). The key mediator of these changes is the transcription factor HIF-1, a heterodimer of the protein subunits HIF-1 alpha, which is induced by hypoxia and HIF-1 beta, which is constitutively expressed (Wang et al, 1995). HIF-1 alpha protein is mainly regulated post-transcriptionally by inhibiting its ubiquitination and proteolysis (Huang et al, 1998). It is known that HIF-1 alpha ultimately leads to HIF-1-regulated gene expression, such as HMOX-1 and VEGF (Bussolati and Mason (2006)). We therefore assumed that bortezomib induced upregulation of HIF-1 alpha by inhibiting proteolysis, thereby, upregulation of HMOX-1 via HIF-1 alpha leads to bortezomib-induced cell death. In the current study, however, upregulation of HIF-1 alpha was not evident at either the transcriptional level or the protein level in TaY cells. 
A

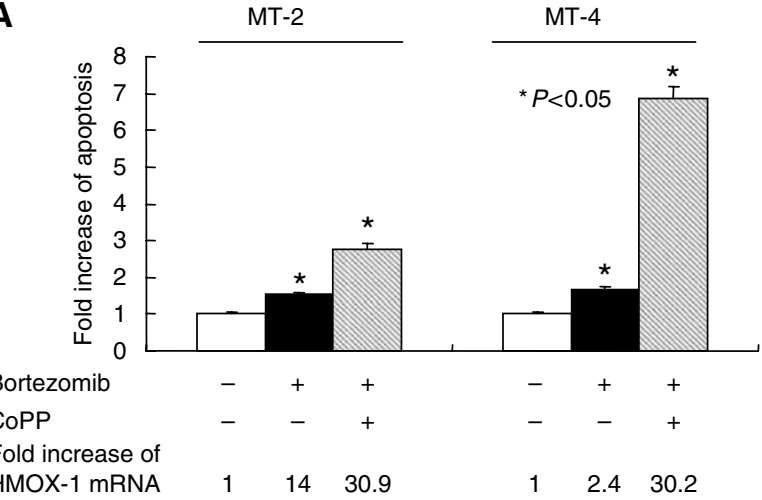

B

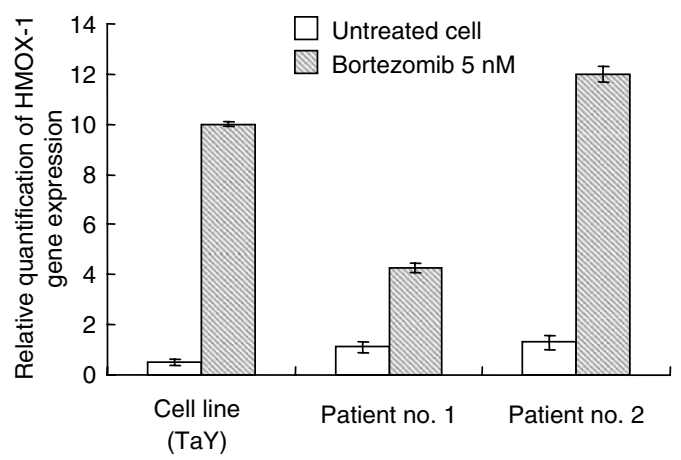

Figure 5 (A) Induction of HMOX-I by CoPP enhances apoptotic effects of bortezomib in MT-2 and MT-4 cells. Fold increase of HMOX-I mRNA is shown at the bottom of the graph. (B) Comparison of gene expression levels between cell line (TaY) and patient sample. Percent of ATL cells in the blood specimens is $46 \%$ in patient no. I and $82 \%$ in patient no. 2, respectively. Relative gene expression levels are expressed as ratios (copy numbers of target gene/copy numbers of GAPDH). In the presence of bortezomib, upregulation of HMOX-I is evident in both TaY cells and patient samples.

Cobalt protoporphyrin is known to be a potent and effective inducer of HMOX-1 in many tissues. Unlike haem, CoPP is neither a pro-oxidant nor a substrate for HMOX-1, therefore, it might be considered as a potential therapeutic agent in situations where upregulation of HMOX-1 is desired. In the current study, CoPP induced HMOX-1 expression. Instead, HIF-1 alpha expression was downregulated by CoPP, possibly due to a feedback mechanism for upregulation of HMOX-1. This further suggests that bortezomib modulates the oxygen-dependent gene regulation, and induction of oxygen-dependent genes may serve as a feedback mechanism to balance the intracellular level of ROS. Since HIF-1 alpha activates the transcription of genes that are involved in cell survival as well as apoptosis, we could not completely rule out the possibility that subtle change of HIF-1 alpha modulates bortezomib-induced cell death via pathways other than those involving HMOX-1. To the best of our knowledge, this is the first report that induction of HMOX-1 by CoPP enhances bortezomib-induced apoptosis.

Although we were able to identify only a limited number of genes related to bortezomib-induced cell death in ATL cells, we demonstrated that HMOX-1 regulation plays an important role in the antitumour activity of bortezomib. Since the number of patients studied was too small to draw a definite conclusion, it should obviously be clarified in large numbers of patient specimen; however, the enhanced sensitivity of ATL cells to bortezomib by CoPP is intriguing and suggests that HMOX-1 may be an attractive target for treating ATL patients.

\section{ACKNOWLEDGEMENTS}

We are indebted to Professor J Patrick Barron of the International Medical Communications Center of Tokyo Medical University for his review of this manuscript. We thank Dr Masanori Daibata (Kochi University) for providing cell lines, MT-2 and MT-4, and Ms Ayako Hirota, for her technical assistance. This work was supported by a 'High-Tech Research Center' Project for private universities: matching fund subsidy from the MEXT (Ministry of Education, Culture, Sports, Science and Technology, 2003-2007), and by the 'University-Industry Joint Research Project' for private universities: matching fund subsidy from the MEXT, 2002-2006, and a grant from MEXT, 2004-2007 (to JHO).

Supplementary Information accompanies the paper on British Journal of Cancer website (http://www.nature.com/bjc)

\section{REFERENCES}

Bussolati B, Mason JC (2006) Dual role of VEGF-induced heme-oxygenase1 in angiogenesis. Antioxid Redox Signal 8: 1153-1163

Cavo M (2006) Proteasome inhibitor bortezomib for the treatment of multiple myeloma. Leukemia 20: 1341-1352, doi:10.1038/sj.leu. 2404278

Fisher RI, Bernstein SH, Kahl BS, Djulbegovic B, Robertson MJ, de Vos S, Epner E, Krishnan A, Leonard JP, Lonial S, Stadtmauer EA, O'Connor OA, Shi H, Boral AL, Goy A (2006) Multicenter phase II study of bortezomib in patients with relapsed or refractory mantle cell lymphoma. J Clin Oncol 24: 4867-4874, doi: 10.1200/JCO.2006.07.9665

Fribley A, Zeng Q, Wang CY (2004) Proteasome inhibitor PS-341 induces apoptosis through induction of endoplasmic reticulum stress-reactive oxygen species in head and neck squamous cell carcinoma cells. Mol Cell Biol 24: 9695-9704, doi: 10.1128/MCB.24.22.9695-9704.2004

Furukawa Y, Tara M, Izumo S, Arimura K, Osame M (2006) HTLV-I viral escape and host genetic changes in the development of adult $\mathrm{T}$ cell leukemia. Int J Cancer 118: 381 -387, doi:10.1002/ijc.21328

Gillis S, Watson J (1980) Biochemical and biological characterization of lymphocyte regulatory molecules. V. Identification of an interleukin 2-producing human leukemia $\mathrm{T}$ cell line. J Exp Med 152: $1709-1719$

Huang LE, Gu J, Schau M, Bunn HF (1998) Regulation of hypoxia-inducible factor 1 alpha is mediated by an $\mathrm{O}_{2}$-dependent degradation domain via the ubiquitin - proteasome pathway. Proc Natl Acad Sci USA 95: 7987 7992, doi:10.1073/pnas.95.14.7987

Kamata H, Honda S, Maeda S, Chang L, Hirata H, Karin M (2005) Reactive oxygen species promote TNFalpha-induced death and sustained JNK activation by inhibiting MAP kinase phosphatases. Cell 120: 649-661, doi:10.1016.j.cell.2004.12.041

Karin M, Ben-Neriah Y (2000) Phosphorylation meets ubiquitination: the control of NF-[kappa]B activity. Annu Rev Immunol 18: 621-663

Landowski TH, Megli CJ, Nullmeyer KD, Lynch RM, Dorr RT (2005) Mitochondrial-mediated disregulation of $\mathrm{Ca}^{2+}$ is a critical determinant of Velcade (PS-341/bortezomib) cytotoxicity in myeloma cell lines. Cancer Res 65: $3828-3836$

Ling YH, Liebes L, Zou Y, Perez-Soler R (2003) Reactive oxygen species generation and mitochondrial dysfunction in the apoptotic response to bortezomib, a novel proteasome inhibitor, in human H460 non-small cell lung cancer cells. $J$ Biol Chem 278: 33714-33723, doi:10.1074/jbcl m302559200

Matsuoka M, Jeang KT (2005) Cancer Res 65: 4467-4470

Mitsiades N, Mitsiades CS, Poulaki V, Chauhan D, Fanourakis G, Gu X, Bailey C, Joseph M, Libermann TA, Treon SP, Munshi NC, Richardson PG, Hideshima T, Anderson KC (2002) Molecular sequelae of proteasome inhibition in human multiple myeloma cells. Proc Natl Acad Sci USA 99: 14374-14379, doi: 10.1073/pnas.202445099 
Miyoshi I, Taguchi H, Kubonishi I, Yoshimoto S, Ohtsuki Y, Shiraichi Y, Akagi T (1982) Type C virus-producing cell lines derived from adult $T$ cell leukiemia. GANN Monogr Cancer Res 28: 219-228

Morse D, Choi AM (2005) Heme oxygenase-1: from bench to bedside. Am J Resp Crit Care Med 172: 660-670, doi:10.1164/rccm.200404-465SO

Nasr R, El-Sabban ME, Karam JA, Dbaibo G, Kfoury Y, Arnulf B, Lepelletier $\mathrm{Y}$, Bex F, de The H, Hermine O, Bazarbachi A (2005) Efficacy and mechanism of action of the proteasome inhibitor PS-341 in T-cell lymphomas and HTLV-I associated adult T-cell leukemia/lymphoma. Oncogene 24: 419-430, doi:10.1038/sj.onc. 1208212

Nawrocki ST, Carew JS, Pino MS, Highshaw RA, Dunner Jr K, Huang P, Abbruzzese JL, McConkey DJ (2005) Bortezomib sensitizes pancreatic cancer cells to endoplasmic reticulum stress-mediated apoptosis. Cancer Res 65: $11658-11666$

Obeng EA, Carlson LM, Gutman DM, Harrington Jr WJ, Lee KP, Boise LH (2006) Proteasome inhibitors induce a terminal unfolded protein response in multiple myeloma cells. Blood 107: 4907-5016, doi:10.1128/blood-2005-08-3531

Ohyashiki JH, Takaku T, Ojima T, Abe K, Yamamoto K, Zhang Y, Ohyashiki K (2005) Transcriptional profiling of human herpesvirus type $\mathrm{B}$ (HHV-6B) in an adult T cell leukemia cell line as in vitro model for persistent infection. Biochem Biophys Res Commun 329: 11-17, doi: 10.1016/j.bbrc.2005.01.090

Ojima T, Abe K, Ohyashiki JH, Shirakata M, Yamamoto K (2005) IL-2regulated persistent human herpesvirus-6B infection facilitates growth of adult T cell leukemia cells. J Med Dent Sci 52: 135-141

Pérez-Galán P, Roué G, Villamor N, Montserrat E, Campo E, Colomer D (2006) The proteasome inhibitor bortezomib induces apoptosis in mantle-cell lymphoma through generation of ROS and Noxa activation independent of p53 status. Blood 107: 257D-264D, doi: 10.1182/blood2005-05-2091

Pierce JW, Schoenleber R, Jesmok G, Best J, Moore SA, Collins T, Gerritsen ME (1997) Novel inhibitors of cytokine-induced IkappaBalpha phosphorylation and endothelial cell adhesion molecule expression show anti-inflammatory effects in vivo. J Biol Chem 272: 21096-21103, doi:10.1074/jbc.272.34.21096

Rajkumar SV, Richardson PG, Hideshima T, Anderson KC (2005) Proteasome inhibition as a novel therapeutic target in human cancer. J Clin Oncol 23: 630 - 639, doi: 10.1200/JCO.2005.11.030
Sakon S, Xue X, Takekawa M, Sasazuki T, Okazaki T, Kojima Y, Piao JH, Yagita H, Okumura K, Doi T, Nakano H (2003) NF-kappaB inhibits TNFinduced accumulation of ROS that mediate prolonged MAPK activation and necrotic cell death. EMBO J 22: 3898-3909, doi:10.1093/emboj/ cdg379

Satou Y, Nosaka K, Koya Y, Yasunaga JI, Toyokuni S, Matsuoka M (2004) Proteasome inhibitor, bortezomib, potently inhibits the growth of adult T-cell leukemia cells both in vivo and in vitro. Leukemia 18: 1357-1363, doi: $10.1038 /$ sj.leu. 2403400

Semenza GL (2003) Targeting HIF-1 for cancer therapy. Nat Rev Cancer 3: 721 - 732, doi:10.1038/nrc1187

Sun SC, Yamaoka S (2005) Activation of NF-kappaB by HTLV-I and implications for cell transformation. Oncogene 24: 5952-5964, doi:10.1038/sj.onc.1208969

Takaku T, Ohyashiki JH, Zhang Y, Ohyashiki K (2005) Estimating immunoregulatory gene networks in human herpesvirus type 6 (HHV6)-infected T cells. Biophys Res Commun 336: 469-477, doi:10.1016/ j.bbrc.2005.08.104

Veschini L, Belloni D, Foglieni C, Cangi MG, Ferrarini M, Caligaris-Cappio F, Ferrero E (2007) Hypoxia-inducible transcription factor-1alpha determines sensitivity of endothelial cells to the proteosome inhibitor bortezomib. Blood 109: 2565-2570 doi: 10.1182/blood-2006-06-032664

Wang GL, Jiang BH, Rue EA, Semenza GL (1995) Hypoxia-inducible factor 1 is a basic-helix-loop-helix-PAS heterodimer regulated by cellular $\mathrm{O}_{2}$ tension. Proc Natl Acad Sci USA 92: 5510-5514, doi:10.1073/ pnas.92.12.5510

Yang W, Monroe J, Zhang Y, George D, Bremer E, Li H (2006) Proteasome inhibition induces both pro- and anti-cell death pathways in prostate cancer cells. Cancer Lett 243: $217-227$ doi:10.1016/j.canlet.2005.11.033

Yu C, Rahmani M, Dent P, Grant S (2004) The hierarchical relationship between MAPK signaling and ROS generation in human leukemia cells undergoing apoptosis in response to the proteasome inhibitor bortezomib. Exp Cell Res 295: 555-566, doi:10.1016/j.yexcr.2004.02.001

Zhang Y, Ohyashiki JH, Takaku T, Shimizu N, Ohyashiki K (2006) Transcriptional profiling of Epstein-Barr virus (EBV) genes and host cellular genes in nasal NK/T-cell lymphoma and chronic active EBV infection. Br J Cancer 94: 599-608, doi:10.1038/sj.bjc.6602968

Zhou CF, Abe K, Wang P, Yamamoto K (1998) Susceptibility of the adult T cell leukemia (ATL) cell lines to HHV-6B. Leukemia 12: 1001 